\title{
Open Water Test Series with Modern Five-Bladed Propeller Models
}

\author{
By Kiyoshi Tsuchida, Member* \\ Atsuo Yazaki, Member* \\ Michio Takahashi, Member**
}

\begin{abstract}
The paper records the result of experiments with a systematic series of five-bladed aerofoit propeller models, designed in accordance with present-day practice.

1 Charts of series are shown by so called $\sqrt{B_{p}}-\delta$ design diagrams.

\section{Introduction}

Nowadays, five bladed propellers are widely equipped to many ships. However, design diagrams based on open water test series with five--bladed propeller models are hitherto unpublished except Prof. Ir. L. Troost's papers. In this report, authors write the result of experiments. with a systematic series of five-bladed AU-series propeller models carried out in the Experiment Tank of Ship Propulsion Division, Transportation Technical Research Institute of Transportation Ministry.
\end{abstract}

\section{Propeller Models}

Forms of AU-series propeller models used in the experiments are shown in Fig. 1, and:

GENERAL PLAN OF AU-SERIES PROPELLER MODELS

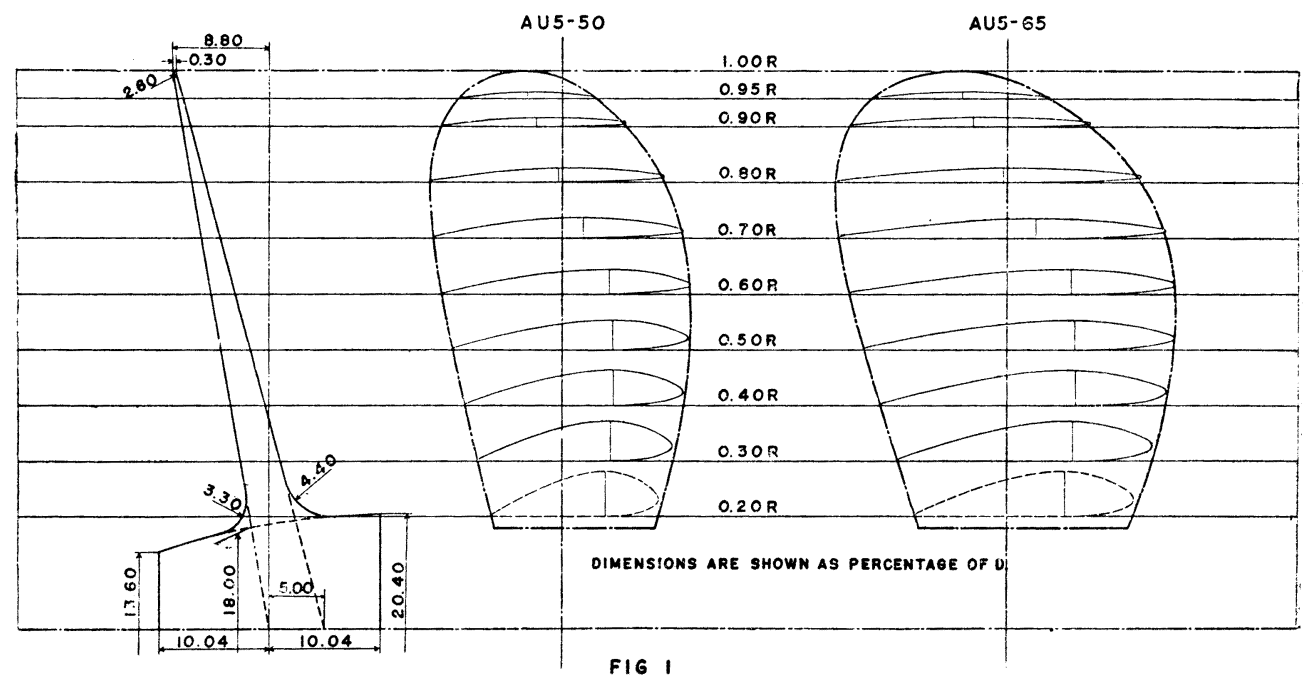

原稿受付. 7 月 15 日

* Ship Propulsion Division, Transportation Technical Research Institute

** Amagasaki Iron and Steel Mfg. Co. Ltd. 
TABLE । PARTICULARS OF AU-SERIES PROPELLER MODELS

\begin{tabular}{l|c|c}
\hline & AU5:50 & AU5-65 \\
\hline DIAMETER(M) & 0.250 & 0.250 \\
BOSS RATIO & 0.180 & 0.180 \\
EXP. AREA RATIO & 0.500 & 0.650 \\
MAXX BLADE WIOTH RATIO & 0.226 & 0.294 \\
BLADE THICKNESS RATIO & 0.050 & 0.050 \\
ANGLE OF RAKE & $10^{\circ} 0^{\circ}$ & $10^{\circ} 0^{\circ}$ \\
NUMBER OF BLADES & 5 & 5 \\
\hline
\end{tabular}

particulars in Table 1. Consider- ing the ever-increasing speed and power of modern ships, the form of blade section, contour of blade, disc area, blade thickness, boss ratio etc. are prefered.

Experiments have been done in two series of expanded-area ratio namely 0.50 and 0.65 , in order to provide means of interpolation and extrapolation, and as to pitch ratio, have been investigatedin $0.4,0.6$ 0.8,1.0 and 1.2. Pitch distribution is constant from

the boss to the tip.

All propeller models of $\mathrm{AU}$-series have a diameter of $250 \mathrm{~mm}$.

Particulars and ordinates of propeller forms and blade sections of AU-series are given in Tables $2 \mathrm{~A}$ and $2 \mathrm{~B}$

IABLE. $2 A$

\begin{tabular}{|c|c|c|c|c|c|c|c|c|c|c|c|c|}
\hline \multirow{4}{*}{$\begin{array}{l}\text { WIDTHS OF BLADE AS } \\
\text { PERCENTAGE OF MAX } \\
\text { BLADE WIOTH }\end{array}$} & $T / R$ & 0.2 & 0.3 & 0.4 & 0.5 & 06 & 0.66 & 0.7. & 08 & 09 & 10 & \multirow{4}{*}{$\begin{array}{l}\text { MAX. BLADE WIDTH AT } \\
\text { O.66r/R.0 } 2260 \\
\text { FOR Fo/F. O } 50\end{array}$} \\
\hline & $\begin{array}{l}\text { FROM GENERATOR-LINE } \\
\text { TO TRAILING EDGE }\end{array}$ & 27.98 & 33.45 & 3876 & 43.54 & 47.96 & 49.74 & 5133 & 52.39 & 48.49 & 1729 & \\
\hline & $\begin{array}{l}\text { FROM GENERATOR-LINE } \\
\text { TO LEADING EDGE }\end{array}$ & 3858 & 44.25 & 48.32 & 50.80 & 51.15 & 5026 & 48.31 & 40.53 & 2513 & & \\
\hline & TOTAL BLADE WIDTH & 66.54 & 77.70 & 8708 & 94.34 & 99.11 & 100.00 & 99.64 & 92.92 & 73.62 & & \\
\hline \multicolumn{2}{|c|}{ BLADE THICKNESS AS PERCENTAGE OF $D$} & 406 & 360 & 3.13 & 2.66 & 2.19 & 191 & 1.72 & 1.26 & 0.79 & Q 32 & $\begin{array}{l}\text { MAX BLADE THICKNESS AT } \\
\text { PROPELLER AXIS }=0050\end{array}$ \\
\hline \multicolumn{2}{|c|}{$\begin{array}{l}\text { DISTANCE OF THE POINT OF MAX THICKNESS } \\
\text { FROM THE LEADING EDGE AS PERCENTAGE OF } \\
\text { BLADE WIDTH }\end{array}$} & 320 & 320 & 32.0 & 32.5 & 34.9 & 37.9 & 402 & 45.4 & 48.9 & & \\
\hline
\end{tabular}

TABLE $2 B$

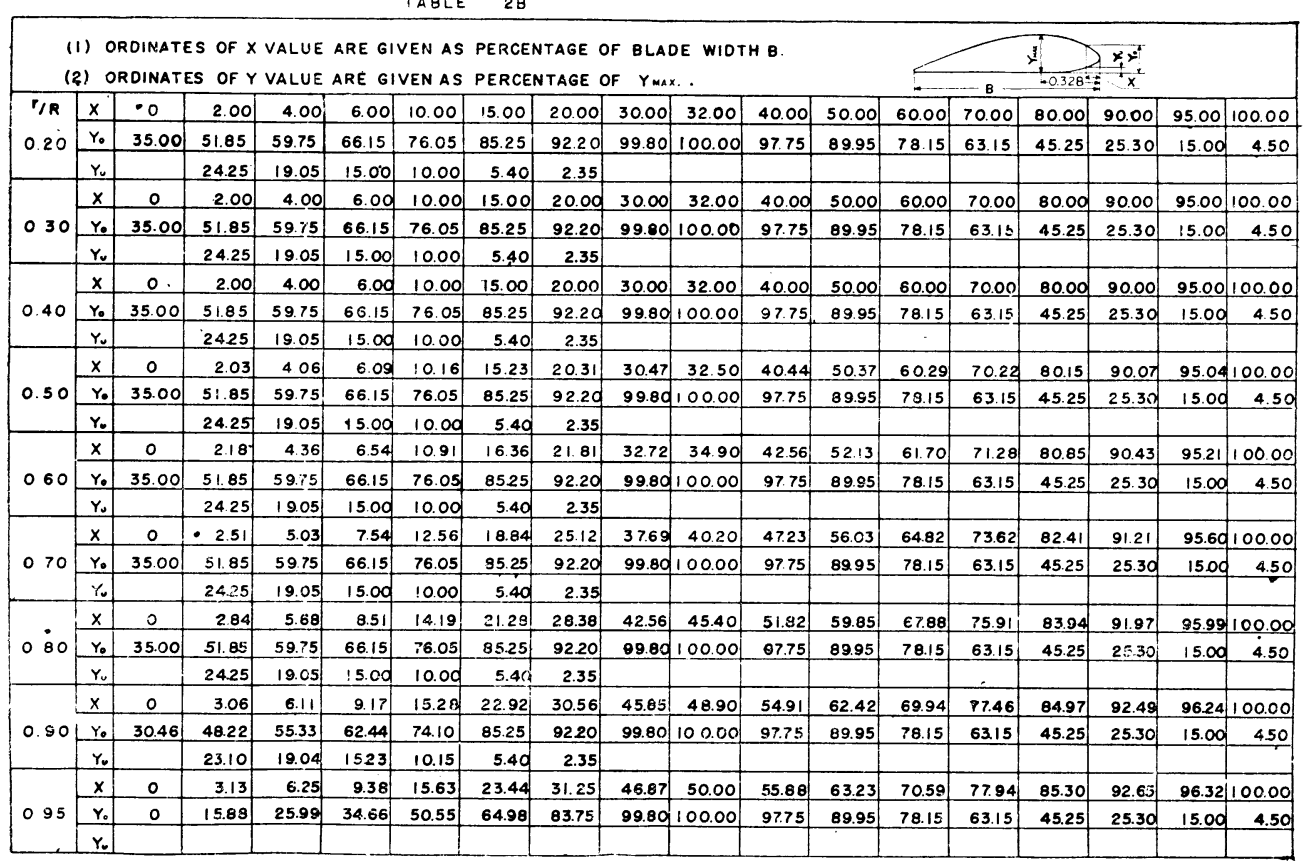




\section{Open Water Tests}

The tests were carried out by means of a propeller open water test dynamometer, according to the scheme of the Experiment Tank of Ship Propulsion Division. The arrangement of the test instruments is shown in Fig. 2. All propeller models have been tested over a $100 \%$ slip range at an immersion to the centre of propeller shaft equal to the screw diameter, and the number of revolutions was kept constant, namely 11 revolutions per seconds, and the speed of advance varied from zero to above the speed for zero thrust.

For fixing the net thrust, the correction for the resistance of the screw hub at various speeds of advance were applied. Mean temperature of water among these tests is $7^{\circ} \mathrm{C}$., and the Reynolds numbers according to the following formulars are as in Table 3. So, it is considered scale effect is negligible.

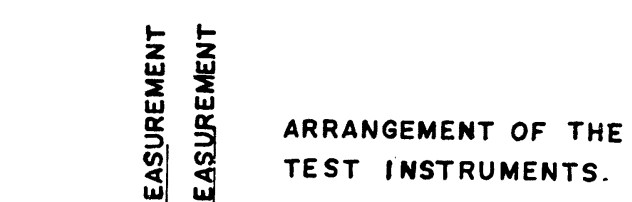

$$
\begin{aligned}
& R=\frac{n D^{2}}{v} \\
& R=\frac{a_{e}}{z} \frac{n D^{2}}{v} \\
& R=\frac{n D^{2}}{v} b_{m n}
\end{aligned}
$$$$
\text { TEST INSTRUMENTS. }
$$

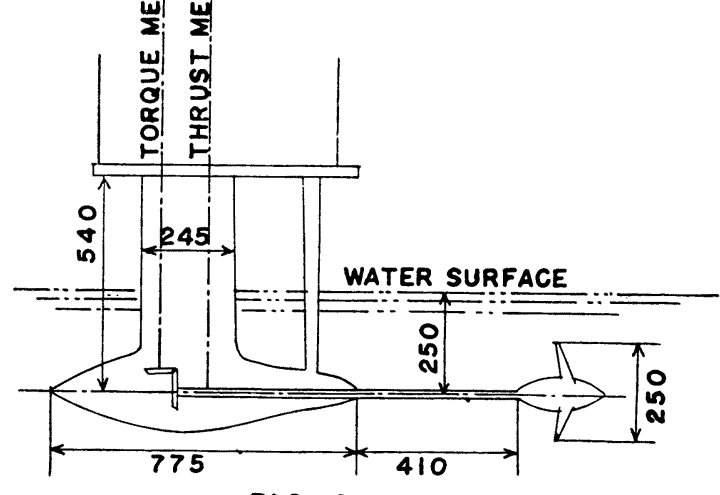

FI6. 2

$n=$ Revolutions per sec. $\quad D=$ Diameter of screw $a_{e}=$ Expanded area ratio

$z=$ Number of blades $\quad b_{m n}=$ Mean blade width ratio $\quad v=$ Kinematic viscosity coefficient $R=$ Reynolds numbers

TABLE 3
LIST OF REYNOLDS NUMBERS
\begin{tabular}{|c|c|c|c|}
\hline TYPE & FORMULA(1) & FORMULA (2) & FORMULA (3) \\
\hline AU5-50 & $4.84 \times 10^{8}$ & $4.84 \times 10^{4}$ & $9.27 \times 10^{4}$ \\
\hline AU5-65 & $4.84 \times 10^{5}$ & $6.29 \times 10^{4}$ & $12.08 \times 10^{4}$ \\
\hline
\end{tabular}

\section{Diagrams}

(a) Curves of $K_{t}, K_{q}$, and $\eta_{p}$ on a based of $\mathrm{J}$.

These curves are given in Figs 3 . and 4 . The meaning of symbols is as follows : -

$K_{t}=$ Thrust constant $=T / \rho n^{2} D^{4}$

$K_{1}=$ Torque constant

$=Q / \kappa n^{2} D^{5} \quad \eta_{p}=$ Propeller efficiency in open water $=\frac{K_{t} J}{2 \pi K_{q}} \quad J=v_{e} / n D$

$T=$ Measured thrust $Q=$ Measured torque $\quad \rho=$ Density of tank water

(b) $\sqrt{B_{p}}-\delta$ diagrams

In these diagrams, we used metric units, and density of sea water is assumed as 104.51

$\mathrm{Kg} \mathrm{m}^{-4} \mathrm{sec}^{-2} . \quad \sqrt{B_{p}}-\delta$ diagrams are given in Figs. 5 and 6.

The meaning of symbols as follows: - 

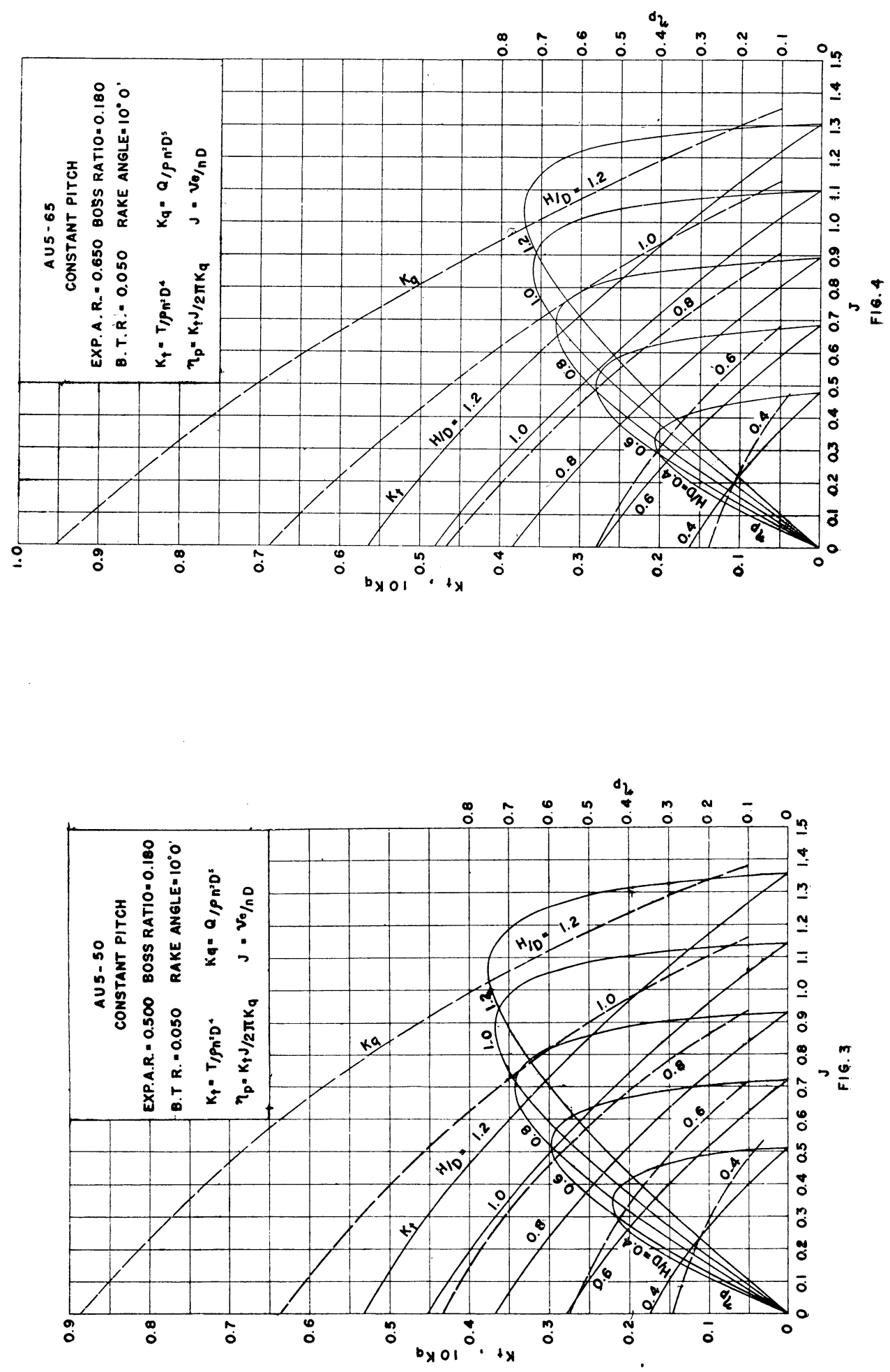

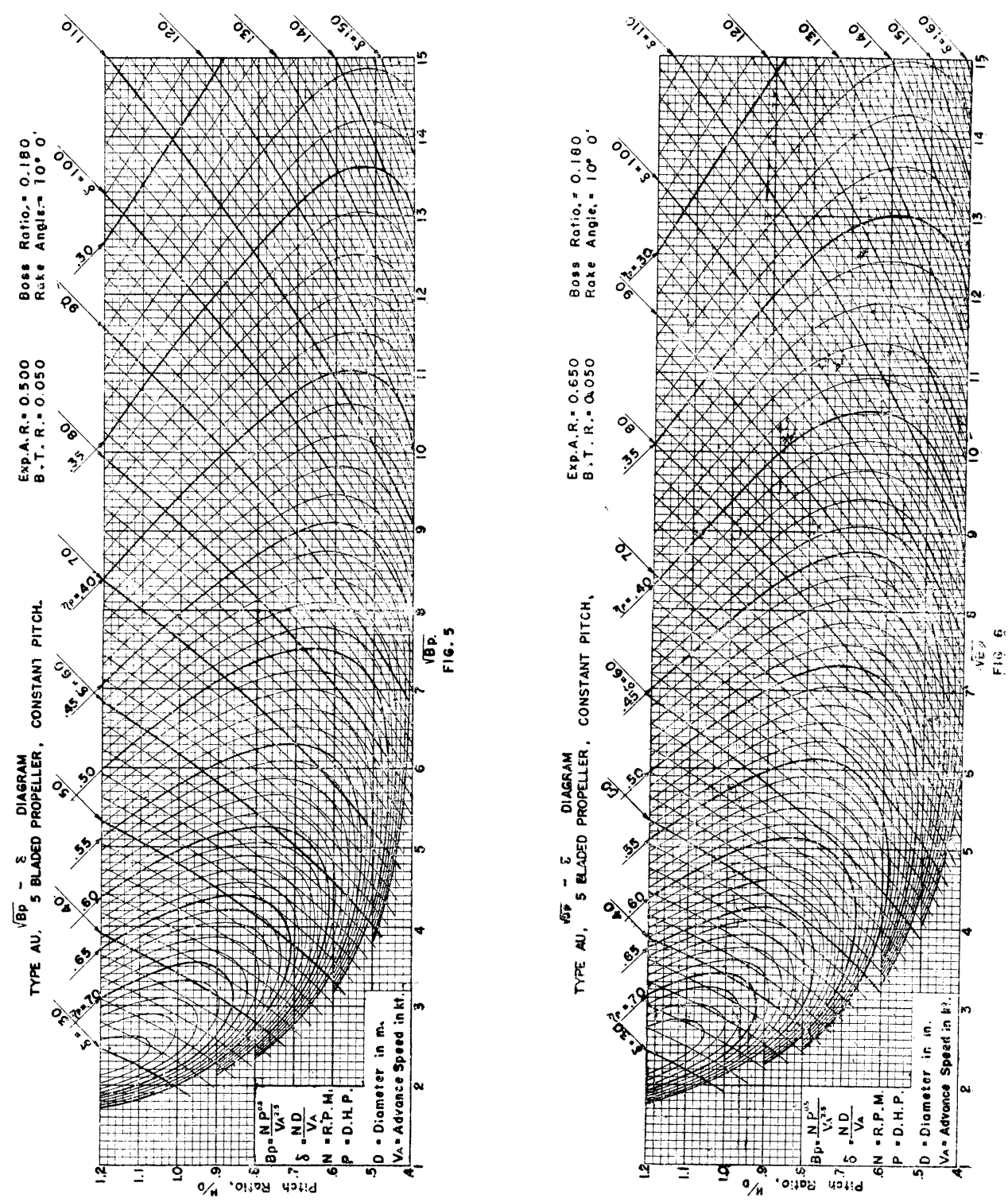
$B_{p}=$ Power coefficient $=\mathrm{NP}^{0.5} / \mathrm{Va}^{2} .5$

$\delta=$ Diameter constant $=\mathrm{ND} / \mathrm{Va}$

$H / D=$ Pitch ratio

$N=$ Revolutions per minute for ship

$P=$ Delivered horse power in sea water

$V_{a}=$ Speed of advance through the wake water in knots

$D=$ Screw diameter in meter

$1 \mathrm{P}=75 \mathrm{~kg} \mathrm{~m} \mathrm{sec}^{-1}$

\section{Comparison of AU 5-50 and AU 5-65}

Optimum values of $\eta_{p}$ of AU 5-50 is better than that of AU 5-65 for all range of J, and its superiority is greater in low pitch ratio. This shows the gap effect is larger in low pitch ratio than in high pitch ratio. Effective pitch ratio is about 4\% smaller in AU 5-65 than in AU5-50.

Table 4 gives optimum values of $\eta_{p}$, diameter constant and pitch ratio for various power constant. From this table, optimum values of $\eta_{p}$ of AU 5-65 is lower, diameter constant is smaller, and pitch ratio is greater than those of $A U 5-50$. In the case of same power and revolutions of ships, therefore, optimum diameter of the propeller of great disc area is small, and pitch ratio is great as comparison with the propeller of small disc area.

\section{TABLE 4}

OPTINUM VALJES OF $\eta_{P}$, DIAMETER CONSTANT 8

AND PITCH RATIO H/D FOR VARIOUS $\sqrt{8 D}$.

\begin{tabular}{|r|c|c|c|c|c|c|}
\hline \multirow{2}{*}{$\sqrt{E p}$} & \multicolumn{3}{|c|}{$A U 5-50$} & \multicolumn{3}{c|}{$A U 5-65$} \\
\cline { 2 - 7 } & $\eta_{p}$ & $\delta$ & $H / D$ & $\eta_{p}$ & $\delta$ & $H / D$ \\
\hline 4.0 & 0.672 & 46.7 & 0.888 & 0.664 & 46.0 & 0.928 \\
\hline 6.0 & 0.564 & 67.0 & 0.720 & 0.556 & 65.3 & 0.770 \\
\hline 8.0 & 0.483 & 86.0 & 0.635 & 0.475 & 84.0 & 0.689 \\
\hline 10.0 & 0.425 & 104.0 & 0.583 & 0.414 & 101.8 & 0.635 \\
\hline 12.0 & 0.380 & 121.8 & 0.550 & 0.368 & 119.0 & 0.598 \\
\hline 14.0 & 0.343 & 138.9 & 0.525 & 0.334 & 136.0 & 0.570 \\
\hline
\end{tabular}

\section{Acknowledgement}

Authors wish to thank Mr. Shiro Kan (Vice-President of Transportation Technical Research Institute). Mr. late Nobutsune Masaki (Amagasaki Iron and Steel Mfg. Co. Ltd.), Mr. Tadao Kondō (Kure Shipbuilding and Engineering Co. Ltd.)and the staff of the Experiment Tank, especially Mr. Yoshiro Kawakami and Mr. Akiyoshi Okumoto, for their valuable assistance in the evaluation of the experiments and the preparation of the propeller charts. 